\title{
PAPER
}

Cite this: Phys. Chem. Chem. Phys. 2014, 16, 11236

Received 1st September 2013

Accepted 21st November 2013

DOI: $10.1039 / c 3 c p 53691 b$

www.rsc.org/pccp

\section{Impact of co-adsorbed oxygen on crotonaldehyde adsorption over gold nanoclusters: a computational study $+\frac{1}{+}$}

\author{
Constantinos D. Zeinalipour-Yazdi, ${ }^{\text {ab }}$ David J. Willock, ${ }^{* \mathrm{~b}}$ Andreia Machado, \\ Karen Wilson ${ }^{c}$ and Adam F. Lee*ad
}

\begin{abstract}
Crotonaldehyde (2-butenal) adsorption over gold sub-nanometer particles, and the influence of co-adsorbed oxygen, has been systematically investigated by computational methods. Using density functional theory, the adsorption energetics of crotonaldehyde on bare and oxidised gold clusters ( $\mathrm{Au}_{13}$, $d=0.8 \mathrm{~nm}$ ) were determined as a function of oxygen coverage and coordination geometry. At low oxygen coverage, sites are available for which crotonaldehyde adsorption is enhanced relative to bare $\mathrm{Au}$ clusters by $10 \mathrm{~kJ} \mathrm{~mol}^{-1}$. At higher oxygen coverage, crotonaldehyde is forced to adsorb in close proximity to oxygen weakening adsorption by up to $60 \mathrm{~kJ} \mathrm{~mol}^{-1}$ relative to bare Au. Bonding geometries, density of states plots and Bader analysis, are used to elucidate crotonaldehyde bonding to gold nanoparticles in terms of partial electron transfer from Au to crotonaldehyde, and note that donation to gold from crotonaldehyde also becomes significant following metal oxidation. At high oxygen coverage we find that all molecular adsorption sites have a neighbouring, destabilising, oxygen adatom so that despite enhanced donation, crotonaldehyde adsorption is always weakened by steric interactions. For a larger cluster $\left(\mathrm{Au}_{38}, d=1.1 \mathrm{~nm}\right)$ crotonaldehyde adsorption is destabilized in this way even at a low oxygen coverage. These findings provide a quantitative framework to underpin the experimentally observed influence of oxygen on the selective oxidation of crotyl alcohol to crotonaldehyde over gold and gold-palladium alloys.
\end{abstract}

\section{Introduction}

Platinum group metal (PGMs) and gold nanoparticles (NPs) are promising heterogeneous catalysts for the selective aerobic oxidation (selox) of alcohols to aldehydes, providing routes that obviate the use of environmentally harmful inorganic oxidants (e.g. $\mathrm{Cr}^{\mathrm{VI}}$ salts ${ }^{1}$ or permanganates ${ }^{2}$ ) and their associated toxic waste, ${ }^{3}$ handling of hazardous peroxides, or the recovery of expensive organometallic soluble catalysts. Recent research has highlighted $\mathrm{Au},{ }^{4} \mathrm{Pd}^{5,6}$ and bimetallic nanoparticles thereof ${ }^{7-10}$ as atom-efficient selox catalysts, able to operate under mild conditions (e.g. reaction temperatures between $60-160{ }^{\circ} \mathrm{C}$ and

\footnotetext{
${ }^{a}$ Department of Chemistry, University of Warwick, Coventry, CV4 7AL, UK. E-mail: A.F.Lee@warwick.ac.uk

${ }^{b}$ Cardiff Catalysis Institute, School of Chemistry, Cardiff University, Cardiff CF10 3AT, UK. E-mail: willockjd@cardiff.ac.uk

${ }^{c}$ European Bioenergy Research Institute, Aston University, Birmingham B4 7ET, UK

${ }^{d}$ School of Chemistry, Monash University, Victoria 3800, Australia

$\dagger$ Electronic supplementary information (ESI) available: The methodology and unit cell for crotonaldehyde adsorption on $\mathrm{Au}(111)$, the optimized structures of all nanoparticle/adsorbate models and LDOS plots are given. See DOI: 10.1039/ c3cp53691b

\# This Article is Published in Celebration of the 50th Anniversary of the Opening of the Chemistry Department at the University of York.
}

employing ambient air as an oxidant) in non-halogenated solvents, aqueous solutions ${ }^{11}$ or even solventless. ${ }^{7}$ The active site in oxide supported Pd NPs for crotyl alcohol selox has been extensively investigated by in situ and operando X-ray spectroscopies. ${ }^{12-15}$ These reveal that oxygen is critical in weakening the adsorption of the reactively-formed crotonaldehyde product thereby reducing decarbonylation pathways. We have made similar observations over $\operatorname{Pd}(111)^{16}$ and $\mathrm{Au} / \mathrm{Pd}(111)^{9,17}$ model single-crystal catalysts, wherein in situ XPS and TPRS measurements show that pre-adsorbed oxygen weakens crotonaldehyde adsorption over pure palladium and Au/Pd surface alloys, thus suppressing undesired decarbonylation pathways. This contrasts with epoxidation wherein oxygen promotes ethene adsorption over silver. ${ }^{18}$ Enhanced activity of Au/Pd core shell nanoparticles in crotyl alcohol selox has been rationalized by $d$-charge depletion observed via XANES measurements. ${ }^{10}$

Chin et al. recently explored the influence of co-adsorbed oxygen on methane combustion over Pd and Pt NPs, ${ }^{19,20}$ while ethanol selective oxidation to ethanal was studied over Au NPs via DFT calculations by Boronat and Corma, ${ }^{21}$ who found that oxygen lowered the activation barriers for $\mathrm{O}-\mathrm{H}$ and $\mathrm{C}-\mathrm{H}$ scission. Delbecq and Sautet also employed DFT in combination with HREELS $^{22}$ vibrational measurements to study crotonaldehyde 
adsorption over $\mathrm{Pt}(111)^{23}$ and $\mathrm{Pt}_{2} \mathrm{Sn} / \mathrm{Pt}(111)^{24}$ alloys, and thereby understand the influence of Sn additives on catalyst selectivity towards the hydrogenation of crotonaldehyde and other $\alpha-\beta$ unsaturated aldehydes. DFT has also been applied in conjunction with metastable de-excitation spectroscopy to elucidate the molecular adsorption modes and reaction pathways during crotyl alcohol selox over bare $\operatorname{Pd}(111) .^{25}$

In this contribution, the effect of co-adsorbed oxygen on the adsorption of crotonaldehyde is explored for the first time via DFT calculations. In particular, we provide fundamental insight into the impact of co-adsorbed oxygen upon crotonaldehyde adsorption over Au NPs, and discuss the resulting implications for crotyl alcohol selox. We present a systematic computational study of crotonaldehyde adsorption over gold NPs (diameter, $d<1 \mathrm{~nm}$ ) as a function of co-adsorbed oxygen surface coverage and proximity. The configurational space for adsorbed crotonaldehyde on bare $\mathrm{Au}_{13}$ and $\mathrm{Au}_{38}$ NPs and their oxidised analogues $\left(\mathrm{Au}_{13} \mathrm{O}_{n}, n=2,4,6\right.$ and 8 and $\left.\mathrm{Au}_{38} \mathrm{O}_{2}\right)$ at effective oxygen coverages between 0-1 monolayers has been explored, and associated adsorption energies calculated. For low oxygen coverage on $\mathrm{Au}_{13}$ particles we find that crotonaldehyde adsorption can be enhanced relative to the bare Au cluster. However, strong destabilisation of crotonaldehyde by co-adsorbed oxygen is found at full oxygen coverage because adsorbed oxygen adatoms occupy positions close to the molecular adsorption site. The concepts discussed are likely extendable to other PGM NPs, and suggest that controlling oxygen surface coverage in situ may aid process optimization during the catalytic selox of allylic alcohols.

\section{Methods}

$\Gamma$ point $^{26}$ DFT calculations were performed with the VASP 5.2 code. $^{27,28}$ Exchange and correlation effects are considered within the generalized gradient approximation (GGA) using the Perdew-Burke-Ernzerhof (PBE) exchange-correlation (XC) functional, ${ }^{29}$ with the projector augmented-wave (PAW) method ${ }^{30,31}$ used to represent core states, $1 \mathrm{~s}$ for $\mathrm{C}$ and $\mathrm{O}$, and $1 \mathrm{~s}$ to $4 \mathrm{f}$ for $\mathrm{Au}$. The cut-off energy for the plane-wave basis was set to $400 \mathrm{eV}$. The nanoparticle/adsorbate models were centered within a $25 \times 25 \times 25 \AA$ periodic box to ensure a vacuum gap of 15-20 around the clusters, with most calculated results obtained at the latter gap. Geometry optimizations of all the atoms in the clusteradsorbate system were performed with a residual force threshold of $0.015 \mathrm{eV} \AA^{-1}$ using the conjugate-gradient algorithm. The convergence criterion for electronic relaxation was $10^{-4} \mathrm{eV}$. The initial charge density was obtained by superposition of atomic charges, and the projection operators were evaluated in reciprocal space. Spin polarization has been tested in several models but found to be unimportant, with calculated adsorption energies agreeing to within $0.5 \mathrm{~kJ} \mathrm{~mol}^{-1}$ for calculations with and without spin polarisation.

Molecular gas phase optimizations were also performed with the Gaussian09 code (rev C.01) ${ }^{32}$ to allow comparison of results with the Becke's three-parameter, hybrid exchange functional ${ }^{33}$ combined with the Lee-Yang-Parr non-local correlation functional, ${ }^{34}$ abbreviated as B3LYP, using the aug-cc-pVTZ ${ }^{35}$ basis set. Linear dependencies of the basis functions were removed by using the spherical version $(5 \mathrm{~d}, 7 \mathrm{f})$ of the aug-cc-pVTZ basis set.

Adsorption energies $\left(E_{\text {ads }}\right)$ were calculated by subtracting the total energy of the fully-relaxed, isolated adsorbace anci nanoparticle from the total energy of the adsorbate-nanoparticle system.

The degree of adsorption-induced charge transfer was estimated through the atomic charges calculated by Bader's atomsin-molecules method using the numerical grid based approach developed by Henkelman and co-workers. ${ }^{36,37}$ These authors have noted that the convergence of Bader charges requires the charge density to be produced on a fine grid so that the spacing between grid points is of the order of $0.02 \AA .{ }^{37}$ VASP works with two grids to represent the charge density, and outputs the finer grid for analysis. The memory requirement for such calculations on the $25 \AA$ cube used to isolate the clusters within the periodic boundary conditions of the simulation was prohibitive on our resources. Accordingly, charge analysis was carried out for each system within a $16 \AA$ cubic simulation cell using the structures optimized within the larger cell. This allowed us to produce a grid with 700 points on a side corresponding to a grid spacing of $0.023 \AA$. As a check on the numerical accuracy of the analysis we carried out additional calculations for ethene adsorbed in a di- $\sigma$ fashion to the $\mathrm{Au}_{13}$ cluster. In this case Bader analysis gave $\mathrm{C}$ atom charges of $-0.1664|e|$ and $-0.1640|e|$. Since the carbon atoms for ethene should be equivalent by symmetry we infer a numerical accuracy of $0.005|e|$. Accordingly, Bader charges are quoted to two decimal places throughout the manuscript. These ethene calculations help inform on $\mathrm{C}=\mathrm{C}$ double bond interactions with the various clusters studied, and provide an additional reference point for discussing the crotonaldehyde results.

\section{Results and discussion}

The rotational isomers of free crotonaldehyde were first optimized to determine the lowest energy gas phase conformers. We found four local minima on the potential energy surface, denoted as $\boldsymbol{E}$-(s)-trans, $\boldsymbol{E}$-(s)-cis, $\boldsymbol{Z}$-(s)-trans and $\boldsymbol{Z}$-(s)-cis as depicted in Fig. 1a-d. The heavy atom molecular framework of all rotamers was found to be planar, indicative of $\pi$-conjugation of the $\mathrm{C}=\mathrm{C}$ and $\mathrm{C}=\mathrm{O}$ moieties. As expected for rotational isomers, there is a negligible change of the corresponding bond lengths between the various isomers. The ordering of the relative energies for the four rotamers was found to be $\boldsymbol{E}$-(s)-trans $\left(-16.0 \mathrm{~kJ} \mathrm{~mol}^{-1}\right)<$ $\boldsymbol{E}$-(s)-cis $\left(-6.6 \mathrm{~kJ} \mathrm{~mol}^{-1}\right)<Z$-(s)-trans $\left(-4.2 \mathrm{~kJ} \mathrm{~mol}^{-1}\right)<Z$-(s)-cis $\left(0.0 \mathrm{~kJ} \mathrm{~mol}^{-1}\right)$. Of the four rotational isomers identified, $\boldsymbol{E}$-(s)-transcrotonaldehyde was the most stable in the gas phase, in agreement with microwave spectroscopy experiments ${ }^{38}$ on transcrotonaldehyde. It is noteworthy that this energy trend is found for both plane-wave and atom-centered basis (i.e. B3LYP/aug-cc-pVTZ) methodologies. Subsequently we have used $\boldsymbol{E}$-(s)-trans to evaluate the effect of co-adsorbed oxygen on the adsorption strength of the desirable product in the selective oxidation of crotyl alcohol, although the general conclusions that follow have also been validated for the second lowest energy conformer $(\boldsymbol{E}$-(s)-cis). 


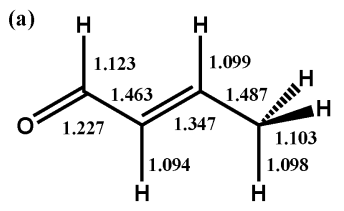

(a)

$$
\text { E-(s)-trans }
$$

(c)

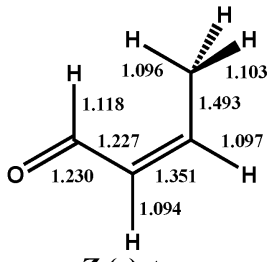

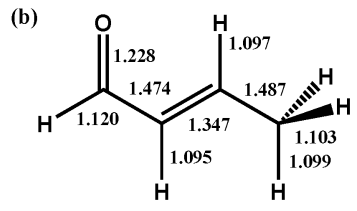

(d)

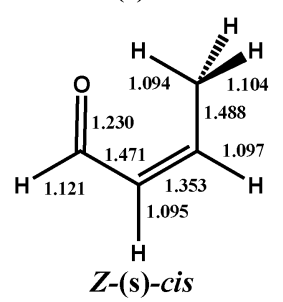

Fig. 1 Structure and nomenclature of rotational isomers of crotonaldehyde obtained at $E_{\text {cut }}=400 \mathrm{eV}$ in a $25 \times 25 \times 25 \AA$ periodic cubic cell. All bond lengths given in $\AA$.

For the gold nanoparticle two particle sizes have been used, $\mathrm{Au}_{13}$ and $\mathrm{Au}_{38}$. In each case the structures were taken from bulk gold $\left(\alpha=\beta=\gamma=90^{\circ}, a=b=c=407.82 \mathrm{pm}\right)^{39}$ and fully optimized to their nearest energetic minima. Both $\mathrm{Au}_{13}$ and $\mathrm{Au}_{38}$ NPs expose (100)-like and (111)-like facets which are also found on gold NPs of different geometries. $\mathrm{Au}_{38}$ has previously been described as an efficient catalyst for molecular oxygen dissociation with DFT calculation results being confirmed experimentally. ${ }^{40,41}$ After adsorption of molecular oxygen on a (100) facet a low barrier was calculated to produce O-adatoms in 3-fold hollow sites (h-O) on adjacent (111) sections of the particle. In Fig. 2 we consider the energetics of $\mathrm{h}-\mathrm{O}$ adsorption on an $\mathrm{Au}_{13}$ cluster by plotting the relative energy of the oxidised cluster compared to $\mathrm{Au}_{13}$ and the corresponding number of gas phase $\mathrm{O}_{2}$ molecules as a function of oxygen coverage. Successive addition of oxygen adatoms thermodynamically stabilizes this system due to the formation of linear $\mathrm{O}-\mathrm{Au}-\mathrm{O}$ structures, which have been previously reported during $\mathrm{O}_{2}$ dissociation on gold clusters ${ }^{42}$ and employed as an indicator of gold oxide formation. ${ }^{43}$ In particular, we find the

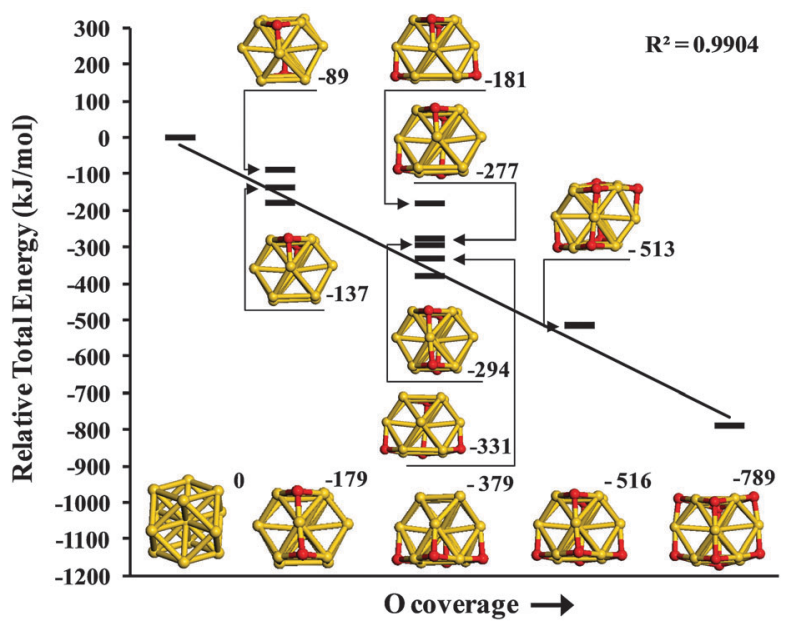

Fig. 2 Relative total energy of $\mathrm{Au}_{13} \mathrm{O}_{n}$, where $n=0,2,4,6$ and 8 for the various possible permutations of three-fold hollow oxygen. The least squares line is drawn for minimum energy structure at each oxygen coverage. relative energy calculated for oxidised $\mathrm{Au}_{13}$ is linearly dependent on the oxygen coverage. This suggests that in an oxidising atmosphere the Au nanoparticles considered here will become surface oxidised.

We note that DFT in general suggests that small isolated clusters of bare gold (e.g. $\left.\mathrm{Au}_{4},{ }^{44} \mathrm{Au}_{12}{ }^{45}\right)$ preferentially adopt a planar structure, whereas larger $\mathrm{Au}_{n}$ clusters $(n>13)$ favour $3 \mathrm{D}$ morphologies that introduce low-coordination edge and vertex sites alongside (100) facets. However, for surface supported nanoparticles, three-dimensional morphologies ${ }^{46,47}$ are observed even for small particles. In the present context we note that oxidation of nanoparticles leads to linear $\mathrm{O}-\mathrm{Au}-\mathrm{O}$ structures ${ }^{42}$ as $\mathrm{Au}$ atoms are oxidized, ${ }^{43}$ and that these will for thermodynamic reasons more easily be accommodated within three dimensional structures. ${ }^{48}$ Accordingly, our use of bulk like structures allows the comparison of crotonaldehyde adsorption as a function of cluster size and oxygen coverage using a consistent cluster geometry which is also in line with the shapes of the supported Au nano-particles used in selox experimentally.

In the subsequent section we explore the various adsorbed configurations of $\boldsymbol{E}$-(s)-trans-crotonaldehyde on nanometer scale Au particles and examine the effect of co-adsorbed oxygen and cluster size on the adsorption energetics. The four lowest energy bound structures for each cluster studied are given in Fig. 3. For the bare $\mathrm{Au}_{13}$ cluster (Fig. 3a) the most favourable adsorption geometry is $\pi_{\mathrm{CC}}$ which is some $15 \mathrm{~kJ} \mathrm{~mol}^{-1}$ lower in energy than the atop and $\mathbf{d i}-\boldsymbol{\sigma}_{\mathbf{C C}}$ modes. The di- $\boldsymbol{\sigma}_{\mathbf{C C}}$ structures

(a)
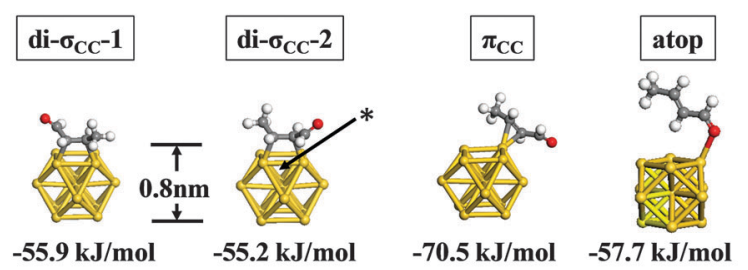

(b)
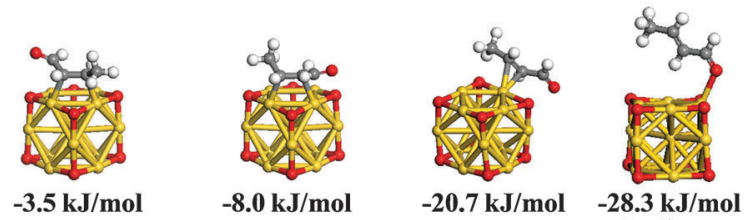

(c)
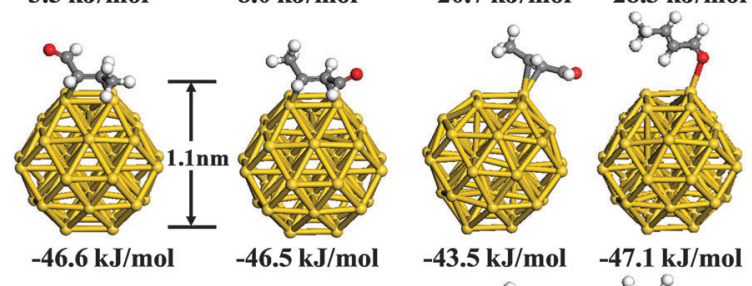

(d)
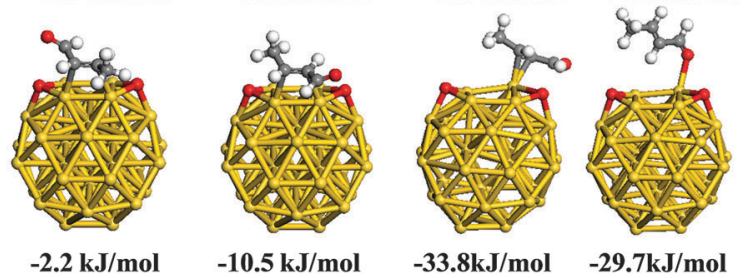

Fig. 3 Adsorption energies of $\mathbf{d i}-\boldsymbol{\sigma}_{\mathbf{c c}}, \pi_{\mathrm{cc}}$ and atop-bonded conformations of $\boldsymbol{E}$-(s)-trans-crotonaldehyde on neutral (a) $\mathrm{Au}_{13}$, (b) $\mathrm{Au}_{13}(\mathrm{~h}-\mathrm{O})_{8}$, (c) $\mathrm{Au}_{38}$ and $(\mathrm{d}) \mathrm{Au}_{38}(\mathrm{~h}-\mathrm{O})_{2}$. 
are akin to ethylene adsorption on neutral, anionic and cationic gold clusters. ${ }^{49}$ For $\boldsymbol{E}$-(s)-trans crotonaldehyde adsorption to the clusters we distinguish two $\mathbf{d i}-\boldsymbol{\sigma}_{\mathbf{C C}}$ geometries; in $\mathbf{d i}-\boldsymbol{\sigma}_{\mathbf{C C}} \mathbf{- 1}$ the aldehyde group is toward an $\mathrm{Au}-\mathrm{Au}$ bridge site while for $\mathbf{d i}-\sigma_{\mathrm{CC}^{-2}} \mathbf{2}$ it is orientated away from the cluster. For $\mathrm{Au}_{13}$ and $\mathrm{Au}_{38}$ (Fig. 3c) these two alternatives are practically isoenergetic. However, for the oxidized clusters $\left(\mathrm{Au}_{13}(\mathrm{~h}-\mathrm{O})_{8}\right.$, Fig. $3 \mathrm{~b}$ and $\mathrm{Au}_{38}(\mathrm{~h}-\mathrm{O})_{2}$, Fig. 3d), locating the aldehyde over the bridge site places this group near an h-O atom, which is more destabilizing than locating the methyl group in the same position such that $\mathbf{d i}-\sigma_{\mathrm{CC}^{-}} \mathbf{2}$ becomes notably lower in energy that $\mathbf{d i}-\boldsymbol{\sigma}_{\mathrm{CC}} \mathbf{- 1}$.

Delbecq and Sautet have provided a survey of adsorption configurations for acrolein (propenal) and crotonaldehyde on $\mathrm{Pt}(111),{ }^{23,24}$ along with calculated adsorption energies using the PW91 functional. For the $\boldsymbol{E}$-(s)-trans isomer they considered five adsorption modes. Two of these adsorb via the $\mathrm{C}=\mathrm{C}$ bond; $\mathbf{d i}-\boldsymbol{\sigma}_{\mathbf{C C}}$ for which $\mathrm{C}=\mathrm{C}$ interacts with two surface $\mathrm{Pt}$ atoms and $\pi_{\mathrm{CC}}$ which involves only a single Pt atom. Adsorption via the $\mathrm{C}=\mathrm{O}$ moiety gives a further two possibilities; di- $\sigma_{\mathrm{CO}}$ and atop with the molecule adsorbed in an end-on fashion through a $\mathrm{Pt} \cdots \mathrm{O}=\mathrm{C}$ interaction. Finally, a $\eta^{4}$ configuration was examined involving both $\mathrm{C}=\mathrm{C}$ and $\mathrm{C}=\mathrm{O}$ bonding to separate $\mathrm{Pt}$ atoms. For crotonaldehyde this latter $\eta^{4}$ adsorption geometry gave the lowest calculated adsorption energy $\left(-84.5 \mathrm{~kJ} \mathrm{~mol}^{-1}\right)$.

The adsorption configurations we have located are in general agreement with the earlier work on Pt. Interestingly, the $\eta^{4}$ structure for adsorbed $\boldsymbol{E}$-(s)-trans crotonaldehyde previously shown to have the potential to undergo decarbonylation over $\operatorname{Pd}(111)^{25}$ was not found on $\mathrm{Au}_{13} \mathrm{O}_{8}$. This implies that oxidised sub-nanometer Au NPs may afford higher crotonaldehyde selectivity rather than decarbonylation, during crotyl alcohol to crotonaldehyde selox. For the remaining configurations, we find that adsorption through the $\mathrm{C}=\mathrm{C}$ bond and $\mathrm{C}=\mathrm{O}$ moieties are possible on both $\mathrm{Au}_{13}$ and $\mathrm{Au}_{38}$ clusters. The NP structure gives rise to edge and corner sites where the facets meet and these are found to be preferred over adsorption on the facets themselves. For $\mathrm{Au}_{13}$ structures bound through the $\mathrm{C}=\mathrm{C}$ moiety generally adsorb more strongly than those via oxygen bound atop (Fig. 3a). However, in the presence of co-adsorbed oxygen we find that atop adsorption actually becomes more favourable (Fig. $3 b$ ). Side reactions that could potentially lead to attack at the allylic bond in the $\mathrm{C}=\mathrm{C}$ bound configurations $\mathbf{~ d i}-\sigma_{\mathrm{CC}} \mathbf{- 1}, \mathbf{d i}-\boldsymbol{\sigma}_{\mathrm{CC}}-\mathbf{2}$ and $\pi_{\mathrm{CC}}$ are thus less probable for oxidized sub-nanometer Au NPs because atop adsorption through the aldehyde oxygen atom is energetically favoured. For $\mathrm{Au}_{38}$ this preference is less clear as the different adsorption modes shown in Fig. $3 \mathrm{c}$ fall within a narrow range $\left(3.6 \mathrm{~kJ} \mathrm{~mol}^{-1}\right)$. We have also examined the adsorption energy of di- $\sigma$ and $\pi$-bound $\boldsymbol{E}$-(s)-trans-crotonaldehyde on $\mathrm{Au}(111)$ (see ESI, $\dagger$ Fig. S1) and found that the adsorption energy is essentially zero $\left(1.1 \mathrm{~kJ} \mathrm{~mol}^{-1}\right)$ indicative that on extended gold surfaces crotonaldehyde can only weakly interact. Comparing the lowest adsorption energies for $\mathrm{Pt}(111),{ }^{22,23} \mathrm{Au}$ NPs and $\mathrm{Au}(111)$ yields the following trend for crotonaldehyde: $\operatorname{Pt}(111)\left(\eta^{4}:-85 \mathrm{~kJ} \mathrm{~mol}^{-1}\right)>\mathrm{Au}_{13}\left(\pi_{\mathrm{CC}}:-71 \mathrm{~kJ} \mathrm{~mol}^{-1}\right)>\mathrm{Au}_{38}$ (atop, di- $\sigma_{\mathrm{CC}^{-1}}$ or di- $\left.\sigma_{\mathrm{CC}^{-}}-2:-47 \mathrm{~kJ} \mathrm{~mol}{ }^{-1}\right)>\mathrm{Au}_{38}(\mathrm{~h}-\mathrm{O})_{2}\left(\pi_{\mathrm{CC}}\right.$ : $\left.-34 \mathrm{~kJ} \mathrm{~mol}^{-1}\right)>\mathrm{Au}_{13}(\mathrm{~h}-\mathrm{O})_{8}\left(\right.$ atop: $\left.-28 \mathrm{~kJ} \mathrm{~mol}^{-1}\right)>\mathrm{Au}(111)$ $\left(1.1 \mathrm{~kJ} \mathrm{~mol}^{-1}\right)$.

It is remarkable that the smaller Au cluster gives an adsorption energy just $14 \mathrm{~kJ} \mathrm{~mol}^{-1}$ less negative than the $\mathrm{Pt}(111)$ value. In contrast, the $\mathrm{Au}_{38}$ value is $38 \mathrm{~kJ} \mathrm{~mol}^{-1}$ less favourable than $\mathrm{Pt}(111)$ whereas on $\mathrm{Au}(111)$ there is practically no interaction at the PBE-level, revealing a strong particle size dependence of the adsorption energy. This weakened adsorption would imply a pronounced particle size-sensitivity for allylic alcohol selox over gold NPs, with the desired crotonaldehyde product preferentially destabilized over larger particles or small NPs that are oxidised (i.e. $\mathrm{Au}_{13} \mathrm{O}_{8}$ ). It is also apparent from Fig. 3 that the energy differences between adsorption to the different sites on a particle fall into a much narrower range for $\mathrm{Au}_{38}\left(3.1 \mathrm{~kJ} \mathrm{~mol}^{-1}\right)$ than for $\mathrm{Au}_{13}\left(15.3 \mathrm{~kJ} \mathrm{~mol}^{-1}\right)$.

Co-adsorbed oxygen exerts an even greater influence on crotonaldehyde adsorption energetics than does particle size. Specifically, we observe a $94 \%, 86 \%, 71 \%$ and $51 \%$ decrease in the magnitude of adsorption energies for $\boldsymbol{E}$-(s)-trans in the di- $\sigma_{\mathrm{CC}}-1, \mathbf{d i}-\sigma_{\mathrm{CC}}-2, \pi_{\mathrm{CC}}$ and atop geometries respectively when $\mathrm{Au}_{13}$ NPs are pre-saturated with oxygen adatoms; this equates to an average decrease of $45 \mathrm{~kJ} \mathrm{~mol}^{-1}$ upon nanoparticle oxidation.

In later sections we will show that for $\mathrm{Au}_{13}$ the weakening of adsorption observed for the di- $\boldsymbol{\sigma}_{\mathbf{C C}}$ geometries on the fully oxidised cluster, $\mathrm{Au}_{13}(\mathrm{~h}-\mathrm{O})_{8}$, occurs due to the proximity of a $\mathrm{h}-\mathrm{O}$ atom at the position closest to the bridge site where the molecule is placed (see asterisk in Fig. 3a). A similar arrangement was constructed for the partially oxidized $\mathrm{Au}_{38}(\mathrm{~h}-\mathrm{O})_{2}$ cluster, however, attempts to locate an oxygen atom in the 3-fold hollow site neighboring the $\mathrm{C}=\mathrm{C}$ bond destabilized $\boldsymbol{E}$-(s)-trans-crotonaldehyde to such an extent that no optimized adsorption geometry could be found. Interestingly we find that if we place an oxygen at the neighbouring 3-fold hollow and keep di- $\sigma$-bound crotonaldehyde at a fixed position, then oxygen diffusion to the adjacent (111)-like facet is observed. However, for $\mathrm{Au}_{38}(\mathrm{~h}-\mathrm{O})_{2}$, the presence of oxygen adatoms at other adjacent sites also decreased the magnitude of crotonaldehyde adsorption by between 10-45 $\mathrm{kJ} \mathrm{mol}^{-1}$ (compare Fig. $3 \mathrm{c}$ and d). Such findings provide evidence for a strong oxygeninduced destabilization of allylic aldehyde adsorption over gold nanoparticles. The origin of this dramatic destabilization, and its oxygen coverage dependence, reflects an intriguing and complex bonding mechanism that we explore in the following sections.

Boronat and Corma have shown that molecular $\mathrm{O}_{2}$ adsorption on the (100) facets of $\mathrm{Au}_{38}$ clusters can yield h-O adatoms on neighbouring (111) facets. We have used the idea of oxygen dissociation on (100) leading to h-O on opposing (111) facets to build-up the oxygen adatom population on an $\mathrm{Au}_{13}$ cluster and examined the effect upon $\boldsymbol{E}$-(s)-trans crotonaldehyde adsorption in the di- $\boldsymbol{\sigma}_{\mathrm{CC}}-\mathbf{2}$ and $\pi_{\mathrm{CC}}$ configurations. The dependence of crotonaldehyde adsorption over $\mathrm{Au}_{13}$ on co-adsorbed oxygen coverage is shown in Fig. 4. In Fig. 4, each structure has an $\mathrm{O}$ atom placed in the hollow site closest to the adsorbate; this clearly has a dramatic effect on the calculated adsorption energy even at low coverage. Indeed for the di- $\sigma_{\mathbf{C C}}$ configuration, dissociation of a single oxygen molecule into such an arrangement leads to $53.1 \mathrm{~kJ} \mathrm{~mol}^{-1}$ fall in 


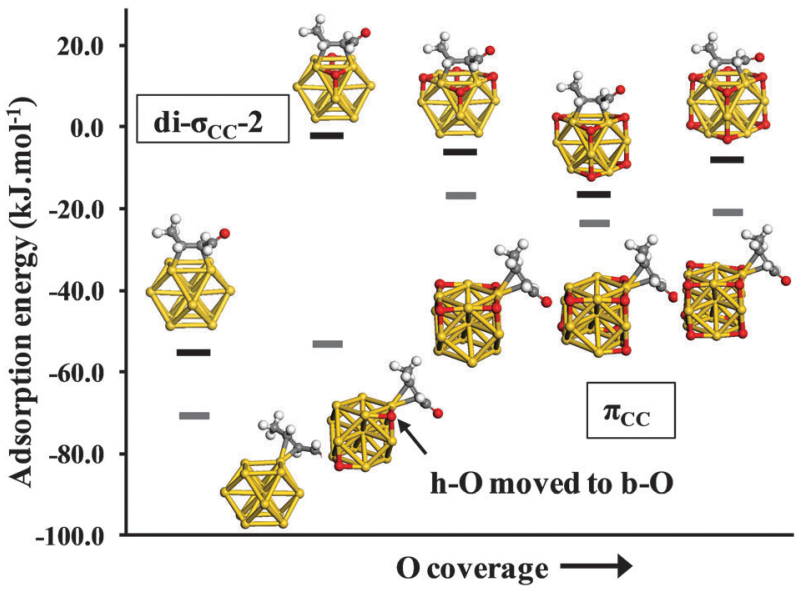

Fig. 4 Adsorption energies of di- $\sigma_{\mathrm{cc}}-\mathbf{2}$ (black lines) and $\pi_{\mathrm{cc}}$ (grey lines) bound $\boldsymbol{E}$-(s)-trans-crotonaldehyde as a function of oxygen coverage on neutral $\mathrm{Au}_{13}$, with an $\mathrm{O}$ adatom positioned in the hollow site proximate to the molecule.

the crotonaldehyde adsorption energy; for intermediate coverages, progressive addition of further oxygen adatoms slightly enhances adsorption with calculated energies increasing from $-2.1\left(\mathrm{Au}_{13}(\mathrm{~h}-\mathrm{O})_{2}\right)$ to $-16.5 \mathrm{~kJ} \mathrm{~mol}^{-1}\left(\mathrm{Au}_{13}(\mathrm{~h}-\mathrm{O})_{6}\right)$.

At full coverage $\left(\mathrm{Au}_{13}(\mathrm{~h}-\mathrm{O})_{8}\right)$ adsorption weakens again, being destabilized by $47.2 \mathrm{~kJ} \mathrm{~mol}^{-1}$ with respect to the bare $\mathrm{Au}_{13}$ cluster. A very similar trend is also observed for the $\pi_{\mathrm{CC}}$ configuration, where on average the adsorption energies are $11 \mathrm{~kJ} \mathrm{~mol}^{-1}$ stronger than for the di- $\sigma_{\mathrm{CC}}$ configuration (excluding $\mathrm{Au}_{13} \mathrm{O}_{2}$ ). For this crotonaldehyde adsorption geometry over $\mathrm{Au}_{13} \mathrm{O}_{2}$, the adjacent h-O shifts away from the aldehyde to a two-fold bridged oxygen (b-O) position, relieving the steric interaction.

Fig. 4 highlights the impact of h-O oxygen atoms located in the (111)-like adsorption site neighboring an adsorbed crotonaldehyde molecule. Such proximate adsorption to the $\mathrm{C}=\mathrm{C}$ bond dramatically reduces the strength of crotonaldehyde adsorption. However, there are clearly other sites available for all intermediate oxygen coverage levels, which are only lost at the point of hollow site saturation $\left(\mathrm{Au}_{13}(\mathrm{~h}-\mathrm{O})_{8}\right)$. Fig. 5 explores the effect of h-O oxygen atom placement on the adsorption of $\boldsymbol{E}$-(s)trans crotonaldehyde in the di- $\sigma_{\mathrm{CC}^{-2}}$ geometry over $\mathrm{Au}_{13}(\mathrm{~h}-\mathrm{O})_{6}$. The results fall into two broad categories. When the proximal h-O site is occupied, crotonaldehyde adsorption is destabilized (as reported in Fig. 4). Fig. 5 reveals that the oxygen adatom arrangement in Fig. 4 actually represents one of the more strongly bound examples of such structures, with crotonaldehyde adsorption varying between +0.8 and $-16.5 \mathrm{~kJ} \mathrm{~mol}^{-1}$. Locating an oxygen adatom in the (111)-like hollow site nearest to the adsorbed molecule weakens crotonaldehyde binding by an average of $59 \mathrm{~kJ} \mathrm{~mol}^{-1}$. By comparison, when the proximal h-O site is unoccupied, crotonaldehyde adsorption is enhanced by between 5.5 and $13.6 \mathrm{~kJ} \mathrm{~mol}^{-1}$ relative to the bare $\mathrm{Au}_{13}$ cluster. This finding has clear implications for practical catalysis, since occupancy of the proximal h-O site can only be guaranteed at saturation oxygen adatom surface coverages, with high binding energy sites for strong crotonaldehyde adsorption available on partially oxidized gold NPs. High oxygen partial pressures/ dissolved concentrations should thus eliminate reaction pathways involving crotonaldehyde adsorption at strongly adsorbing sites which likely favour decarbonylation versus desired competing desorption pathways. Fully oxidized gold NP catalysts are anticipated to disfavour the adsorption of related allylic aldehydes with respect to their naked gold counterparts, and may also interact more weakly with other unsaturated organic molecules that typically coordinate through $\mathrm{C}=\mathrm{C}$ functions.

Of the two clusters explored in the present work, $\mathrm{Au}_{13}$ is unique in that each (111) like facets contains only a single three-fold hollow site. Larger clusters possess extended facets, so that even on $\mathrm{Au}_{38}$ each (111) face contains six hollow sites. Occupancy of all such (111) hollow sites by oxygen adatoms is unlikely since this would place h-O atoms close to one another. Boronat and $\mathrm{Corma}^{21}$ suggest that a $\mathrm{Au}_{38} \mathrm{O}_{16}$ cluster, in which only a third of the available $\mathrm{h}-\mathrm{O}$ sites are occupied, represents a saturated oxide monolayer. In this latter scenario, crotonaldehyde adsorption could away from a neighboring h-O atom. It is noteworthy from Fig. 3 that such open adsorption sites on larger clusters would still be destabilized with respect to the bare cluster by $9.7 \mathrm{~kJ} \mathrm{~mol}^{-1}$ $\left(\pi_{\mathrm{CC}}\right)$ and $44.4 \mathrm{~kJ} \mathrm{~mol}^{-1}$ (di- $\left.\sigma_{\mathrm{CC}}-1\right)$. Hence, nanometre gold nanoparticles partially oxygen covered remain able to adsorb crotonaldehyde with moderate energies $\left(-20\right.$ to $\left.-40 \mathrm{~kJ} \mathrm{~mol}^{-1}\right)$ at sites that are not directly adjacent to oxygen adatoms.

Fig. 5 reveals that oxygen adsorption over for $\mathrm{Au}_{13}$ can either enhance or destabilize crotonaldehyde adsorption, and we now advance a bonding model to explain these observations. The di- $\sigma_{\mathrm{CC}}$ mode of bonding can be viewed in terms of donation from the $\mathrm{C}=\mathrm{C} \pi$-density to empty metal orbitals, and backdonation from the filled metal d-states into the anti-bonding $\pi^{*}$-orbitals of the allylic bond. These combined effects change the structures of $\mathrm{C}=\mathrm{C}$ double bonds as the carbon atoms alter from $\mathrm{sp}^{2}$ toward $\mathrm{sp}^{3}$ geometries. The structural analyses presented in Fig. 6 for crotonaldehyde over bare and oxidized $\mathrm{Au}_{13}$ NPs reveal qualitative trends in line with this model. We find generally shorter $\mathbf{d i}-\sigma_{\mathrm{CC}}$ bond lengths $\left(r_{\mathrm{Au}-\mathrm{C}}\right)$ for the more strongly adsorbed configurations (Fig. 6a) accompanied by a decreased dihedral angle $\varphi_{\mathrm{H}-\mathrm{C} 2-\mathrm{C} 3-\mathrm{H}}$ for crotonaldehyde, indicative of $\mathrm{sp}^{2}$ to $\mathrm{sp}^{3}$ rehybridization of the two $\mathrm{C}$ atoms in the olefinic bond. For metals with a filled d-shell such as $\mathrm{Au}$, we would also expect the interaction with the bare cluster to be dominated by metal to adsorbate back donation.

The sub-set of structures lacking an h-O atom adjacent to crotonaldehyde exhibit stronger $\mathbf{d i -} \sigma_{\mathbf{C C}}-2$ adsorption than occurs on the bare $\mathrm{Au}_{13}$ cluster (Fig. 5). These structures have correspondingly shorter $r_{\mathrm{Au}-\mathrm{C}}$ bonds by $\sim 0.043 \AA$, and smaller $\varphi_{\mathrm{H}-\mathrm{C} 2-\mathrm{C} 3-\mathrm{H}}$ dihedral angles $\left(142^{\circ}\right.$ versus $\left.147^{\circ}\right)$ than for the bare cluster, consistent with strong rehybridization of the two $\mathrm{C}$ atoms in the $\mathrm{C}=\mathrm{C}$ moiety in the presence of h-O adatoms. This likely reflects oxidation of the $\mathrm{Au}$ atoms to which the crotonaldehyde is bound; cationic gold, having a smaller effective radius than the neutral atom species, permits closer approach of the adsorbate, while the associated depopulation of d-states facilitates adsorbate to cluster charge donation in concert with 


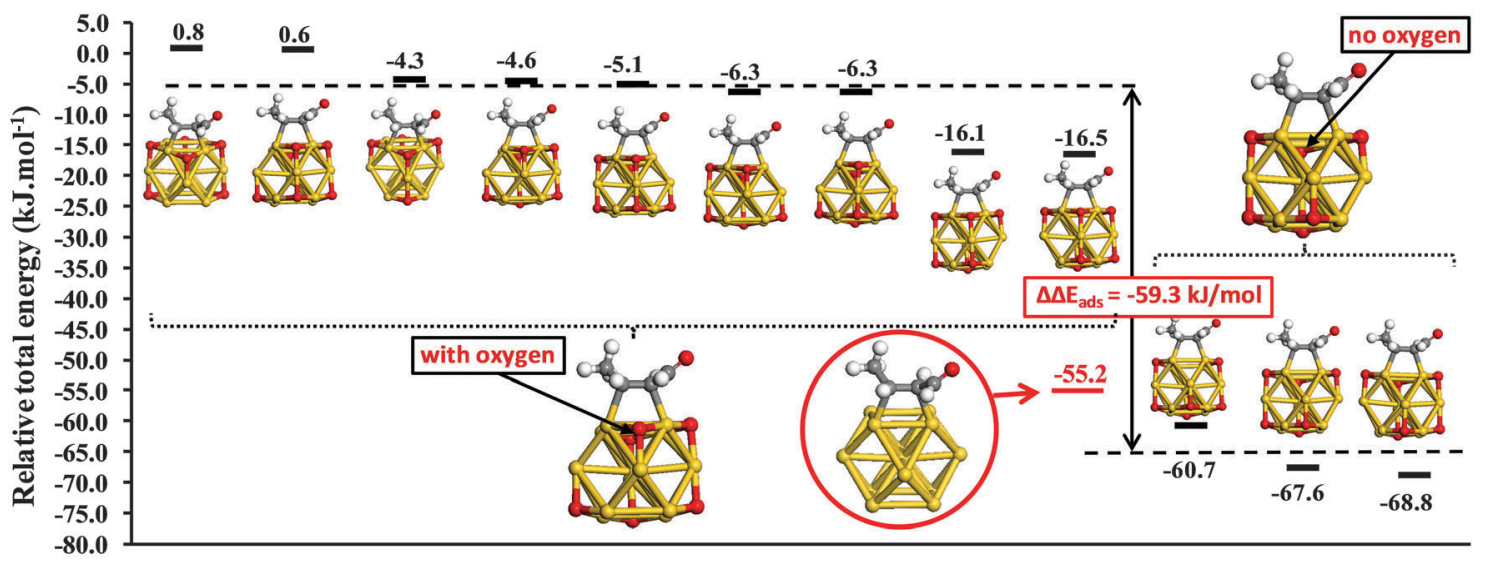

Arrangement of h-O oxygen atoms on $\mathrm{Au}_{13} \mathrm{O}_{6}$

Fig. 5 Adsorption energies of $\boldsymbol{E}$-(s)-trans-crotonaldehyde as di- $\boldsymbol{\sigma}_{\mathrm{cc}}-\mathbf{2}$ for different arrangements of $\mathrm{h}-\mathrm{O}$ oxygen atoms on $\mathrm{Au}_{13}(\mathrm{~h}-\mathrm{O})_{6}$.

(a)

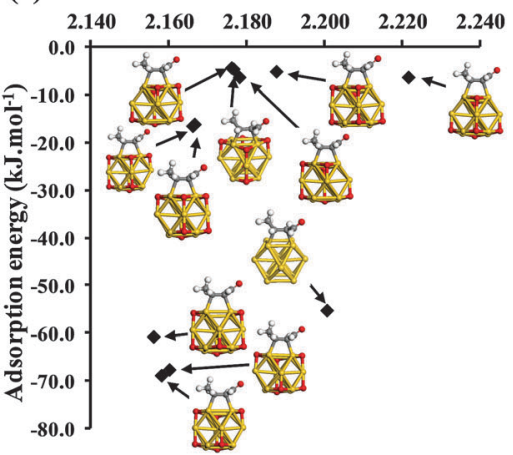

(b)

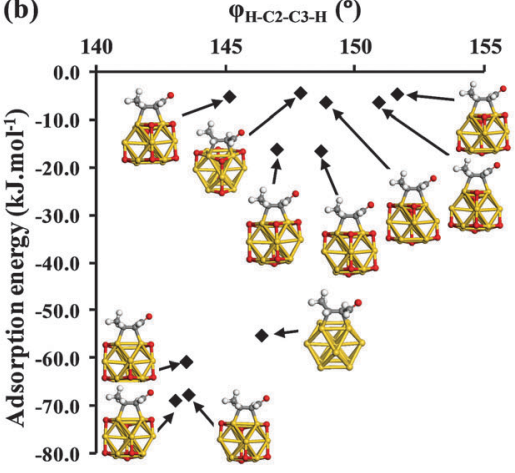

(c)

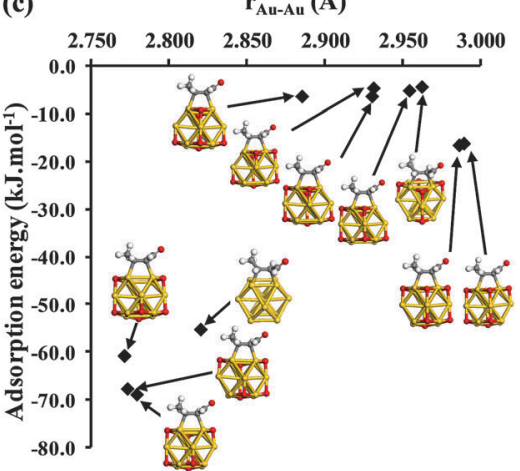

Fig. 6 Relationship between crotonaldehyde adsorption energy $\Delta E_{\text {ads }}$ and (a) average gold-carbon bond length $r_{\mathrm{Au}-\mathrm{C}}$ between crotonaldehyde and $\mathrm{Au}_{13}$ cluster; (b) dihedral bond of crotonaldehyde $\varphi_{\mathrm{H}-\mathrm{C} 2-\mathrm{C} 3-\mathrm{H}}$; and (c) the gold-gold bond length $r_{\mathrm{Au}-\mathrm{Au}}$ following di- $\sigma_{\mathrm{CC}}$ adsorption of $\boldsymbol{E}$-(s)-trans crotonaldehyde. Analysis of geometric parameters was performed on the bare and oxidised $\mathrm{Au}_{13} \mathrm{NPs}$ shown in Fig. 5. Note the two cluster-adsorbate systems with slightly positive adsorption energies in were omitted for clarity.

the metal to adsorbate back donation that also operates on the bare cluster. The two Au atoms coordinating to crotonaldehyde are also $0.046 \AA$ closer in this set of oxidized clusters than they are for the parent $\mathrm{Au}_{13}$ cluster, probably reflecting distortion of the former arising from the stronger $\mathrm{C}=\mathrm{C}$ binding.

A similar picture emerges for the sub-set of structures in which the three-fold hollow site closest to crotonaldehyde is occupied by oxygen, for which aldehyde adsorption is significantly weaker than on bare $\mathrm{Au}_{13}$. These configurations have generally longer $r_{\mathrm{Au}-\mathrm{C}}$ bonds (spanning $2.156 \AA$ to $2.222 \AA$ ) and $\varphi_{\mathrm{H}-\mathrm{C} 2-\mathrm{C} 3-\mathrm{H}}$ dihedral angles closer to the $180^{\circ}$ value expected for the planar $\mathrm{C}=\mathrm{C}$ double bond in the unbound aldehyde. Although the two coordinating $\mathrm{Au}$ atoms in this sub-set are again expected to be electron deficient due to adsorbed oxygen, the attractive interactions from molecule-to-metal electron donation have to be balanced against the steric repulsion between crotonaldehyde and the proximate h-O oxygen atom. Fig. $6 \mathrm{c}$ shows that oxygen adatoms placed near crotonaldehyde significantly increase the separation of $\mathrm{Au}$ atoms to which the $\mathrm{C}=\mathrm{C}$ bond coordinates, resulting in an inverse correlation between aldehyde adsorption and $\mathrm{Au}-\mathrm{Au}$ bond distance.
A simple trigonometric calculation shows that, for $\mathrm{sp}^{3}$ hybridised $\mathrm{C}$ atoms, an $\mathrm{Au}-\mathrm{Au}$ spacing of around $2.80 \AA$ is optimal for $\mathrm{Au}-\mathrm{C}$ distances of $2.16 \AA$, i.e. the most strongly bound clusters have geometries consistent with this bonding geometry at the $\mathrm{C}$ atoms.

Fig. 7 shows a comparison of the Au $5 \mathrm{~d}$ partial density of states (PDOS) for the $\mathrm{Au}_{13}$ cluster and associated $\mathrm{Au}_{13} \mathrm{O}_{6}$ structures. The bare $\mathrm{Au}_{13}$ states range from around -7 to $-1 \mathrm{eV}$ relative to the Fermi level, consistent with the filled $\mathrm{d}$-shell of atomic $\mathrm{Au}$, whereas the $\mathrm{Au}_{13} \mathrm{O}_{6}$ PDOS plots show a broader spread of energies, with unoccupied states present above the Fermi level reflecting the formation of linear $\mathrm{O}-\mathrm{Au}-\mathrm{O}$ bonds and concomitant gold oxidation. Formation of empty metal d-states upon cluster oxidation permits localized adsorbate $\rightarrow$ metal donation as discussed above.

Further insight into the charge distribution of selected configurations was obtained using Bader analysis (Table 1). Fig. 7 shows that the $\mathrm{Au}_{13}$ cluster has filled d-orbitals and so we would expect a net electron donation from the d-orbitals of the bare $\mathrm{Au}_{13}$ cluster to adsorbed crotonaldehyde with negligible back-donation, however only minimal charge transfer $(\Delta q=0.04)$ 


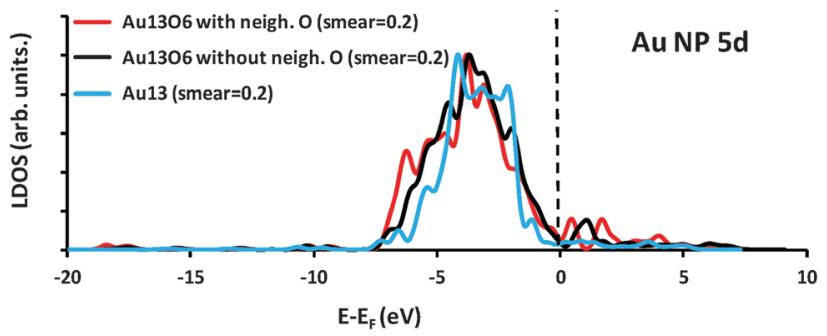

Fig. 7 Comparison of partial density of states (PDOS) for the Au $5 d$ states of $\mathrm{Au}_{13}$ (blue), $\mathrm{Au}_{13} \mathrm{O}_{6}$ with $\mathrm{h}-\mathrm{O}$ at adsorption site (red) and $\mathrm{Au}_{13} \mathrm{O}_{6}$ without $\mathrm{h}-\mathrm{O}$ at adsorption site (black). The Fermi level, $E_{\mathrm{F}}$, is indicated by the vertical dashed line. A smearing parameter of $0.2 \mathrm{eV}$ was used in the VASP calculations with no additional smearing applied to the resulting PDOS data.

is actually calculated. It is worth recalling that gold NPs with odd numbers of electrons, such as the neutral $\mathrm{Au}_{13}$ cluster, exhibit high electron affinities ${ }^{50,51}$ due to the unpaired electron which formally occupies a delocalised state arising from the overlap of Au sp-atomic orbitals. This high electron affinity may allow electron transfer from crotonaldehyde to the cluster and Table 1 suggests that (for $\mathrm{Au}_{13}$ ) these opposing effects selfcompensate. Oxygen addition to $\mathrm{Au}_{13}$ to form $\mathrm{Au}_{13} \mathrm{O}_{6}$ results in a net charge transfer of $4.39 e$ from the cluster to oxygen adatoms, with the six $\mathrm{Au}$ atoms doubly coordinated to $\mathrm{O}_{\mathrm{a}}$ carrying an average charge of $0.49 e$, significantly higher than the quoted average across all $13 \mathrm{Au}$ atoms. Crotonaldehyde adsorption to the $\mathrm{Au}_{13} \mathrm{O}_{6}$ cluster lacking an h-O adatom neighbouring the adsorption site shows significant net electron donation from the aldehyde to the cluster $(\Delta q=-0.13)$, due to the available empty d-orbitals associated with charge withdrawal by the co-adsorbed oxygen, thereby enhancing crotonaldehyde adsorption relative to $\mathrm{Au}_{13}\left(-68.8 \mathrm{~kJ} \mathrm{~mol}^{-1}\right.$ versus $-55.2 \mathrm{~kJ} \mathrm{~mol}^{-1}$ respectively). Bader charge analysis for the $\mathrm{Au}_{13} \mathrm{O}_{6}$ where a neighbouring h-O atom is present, reveals a virtually identical charge distribution to that of oxidized cluster with this site vacant. This implies that the electronic structure of crotonaldehyde binding to $\mathrm{Au}_{13} \mathrm{O}_{6}$ cluster is similar with or without the proximate h-O. Hence the large energy difference of $52.3 \mathrm{~kJ} \mathrm{~mol}^{-1}$ between these configurations and attendant molecular destabilization associated with the former can only be attributed to steric interactions between the neighbouring adsorbed oxygen and the aldehyde. Parallel calculations employing ethene as a model allylic adsorbate offer a similar picture; oxidation of the $\mathrm{Au}_{13}$ cluster promotes adsorption unless the proximal h-O site is occupied. For ethene, the additional stabilization due to the availability of empty d-orbitals upon cluster oxidation is greater than for crotonaldehyde (18.2 versus $13.6 \mathrm{~kJ} \mathrm{~mol}^{-1}$ ). Conversely, ethene destabilization over $\mathrm{Au}_{13} \mathrm{O}_{6}$ by neighbouring h-O is lower $\left(30.9 \mathrm{~kJ} \mathrm{~mol}^{-1}\right)$ than that observed for crotonaldehyde. The charge distributions for adsorbed ethene with and without neighbouring h-O are also essentially identical, confirming that for adsorbates possessing $\mathrm{C}=\mathrm{C}$ bonds, it is repulsive steric interactions that regulate their adsorption over gold nanoparticles, with ethene less sensitive to such factors than the bulkier allylic aldehyde. We note here that the influence of surface oxygen atoms on the adsorption of ethene is considered for comparison with our crotonaldehyde results. The formation of a oxametallacycle akin to that discussed by Linic and Barteau for ethene epoxidation over $\mathrm{Ag}^{52}$ has not been considered.

Table 1 Bader charge analysis of crotonaldehyde $(\mathrm{CrCHO})$ and ethene (Et) adsorption to $\mathrm{Au}_{13}$ and $\mathrm{Au}_{13} \mathrm{O}_{6}$ clusters

\begin{tabular}{|c|c|c|c|c|c|c|c|c|c|}
\hline Structure & $q_{\mathrm{Au}_{13}}{ }^{a} /|e|$ & $q_{\mathrm{O}_{\mathrm{ads}}}{ }^{a} /|e|$ & $\left\langle q_{\mathrm{Au}}\right\rangle^{b} /|e|$ & $\left\langle q_{\mathrm{O}_{\mathrm{ads}}}\right\rangle^{b} /|e|$ & $\Delta q^{c} /|e|$ & $q_{\mathrm{C} 1}{ }^{d} /|e|$ & $q_{\mathrm{C} 2}{ }^{d} /|e|$ & $q_{\mathrm{O} 1}{ }^{e} /|e|$ & $\Delta E_{\mathrm{ads}} / \mathrm{kJ} \mathrm{mol}^{-1}$ \\
\hline $\mathrm{Au}_{13}$ & 0.00 & - & 0.00 & - & - & - & - & - & - \\
\hline $\mathrm{Au}_{13} \mathrm{O}_{6}$ & 4.39 & -4.39 & 0.34 & -0.73 & - & - & - & - & - \\
\hline CrCHO & - & - & - & - & - & -0.05 & -0.09 & -1.10 & - \\
\hline 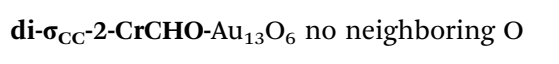 & 4.29 & -4.43 & 0.33 & -0.74 & -0.13 & -0.07 & -0.13 & -1.07 & -68.8 \\
\hline di- $\sigma_{\mathrm{CC}}-2-\mathrm{CrCHO}-\mathrm{Au}_{13} \mathrm{O}_{6}$ with neighboring $\mathrm{O}$ & 4.25 & -4.43 & 0.33 & -0.74 & -0.17 & -0.07 & -0.12 & -1.07 & -16.5 \\
\hline di- $\sigma-E t-\mathrm{Au}_{13} \mathrm{O}_{6}$ no neighboring $\mathrm{O}$ & 4.26 & -4.44 & 0.33 & -0.74 & -0.18 & -0.15 & -0.14 & - & -102.2 \\
\hline di- $\sigma$-Et- $\mathrm{Au}_{13} \mathrm{O}_{6}$ with neighboring $\mathrm{O}$ & 4.22 & -4.43 & 0.32 & -0.74 & -0.21 & -0.14 & -0.13 & - & -53.1 \\
\hline
\end{tabular}

${ }^{a}$ Sum of Bader charges on indicated atom type. ${ }^{b}$ Average Bader charge on indicated atom type. ${ }^{c}$ Charge transfer, negative values indicate $e$ transfer from adsorbate to nanoparticle. ${ }^{d}$ Bader charge on carbon atoms of $\mathrm{C}=\mathrm{C}$ bonded to the cluster, in $\mathrm{CrCHO}_{\mathrm{C} 1} \mathrm{has}^{\mathrm{C}} \mathrm{CH}_{3}$ and $\mathrm{C} 2$ a $\mathrm{CHO}$ substituent. ${ }^{e}$ Bader charge on aldehyde oxygen atom. 
The electronic effect of the substituents on the crotonaldehyde $\mathrm{C}=\mathrm{C}$ bond can also be seen; even for the gas phase molecule the two $\mathrm{C}$ atoms have significantly different Bader charges. On adsorption both $\mathrm{C}$ atoms become slightly more negatively charged but this effect is in-sensitive to the state of the cluster. Further the charge on the aldehyde oxygen atom is practically unchanged from the gas phase for each adsorption mode suggesting that electronic rearrangement within the molecule upon adsorption plays a relatively minor role.

\section{Conclusions}

In this study we find that oxidation of well-defined Au nanoparticles strongly influences crotonaldehyde and ethene adsorption. For the $0.8 \mathrm{~nm}$ diameter $\mathrm{Au}_{13}$ cluster discussed here, intermediate oxygen coverages enhance crotonaldehyde and ethene adsorption through the $\mathrm{C}=\mathrm{C}$ group by $14-18 \mathrm{~kJ} \mathrm{~mol}^{-1}$. This effect can be understood in terms of the genesis of empty $\mathrm{Au}$ d-states in the oxidised clusters able to receive electrons from these allylic adsorbates. At higher oxygen coverages this bonding picture is still valid, however steric interactions between oxygen adatoms neighbouring the crotonaldehyde (ethene) adsorption site destabilize the molecule by up to $60 \mathrm{~kJ} \mathrm{~mol}^{-1}$ with respect to bare $\mathrm{Au}_{13}$. We also find that oxidation of these sub-nanometer gold NPs is likely to be favoured in an oxidising atmosphere, so that under normal selox conditions oxygen will be present on the surface.

Increasing the gold nanoparticle size to $1.1 \mathrm{~nm}\left(\mathrm{Au}_{38}\right)$ lowers the crotonaldehyde adsorption energy by $20-40 \%$ compared to the bare $\mathrm{Au}_{13}$ cluster. Oxidation to $\mathrm{Au}_{38} \mathrm{O}_{2}$, wherein the $\mathrm{O}$ adatoms are located close to co-adsorbed crotonaldehyde, weakens the allylic aldehyde adsorption by as much as $90 \%$.

These calculations highlight the importance of both the surface coverage, and location of adsorbed oxygen upon the stability of co-adsorbed crotonaldehyde, the desired product of crotyl alcohol selox. Oxygen bound in a three-fold hollow site adjacent to adsorbed crotonaldehyde dramatically destabilizes the latter due to strong steric repulsion. This finding implies that crotyl alcohol selox catalysed over gold nanoparticles should be conducted under high oxygen partial pressures, in order to desorb the reactively-formed aldehyde product and prevent side-reactions such as crotonaldehyde decarbonylation to propene and CO. Conversely, low oxygen partial pressures, and concomitant low surface oxygen coverages may hinder crotonaldehyde desorption due to enhanced adsorbate $\rightarrow$ cluster electron transfer relative to unoxidised gold nanoparticles.

\section{Acknowledgements}

We thank the EPSRC (EP/E046754/1; EP/G007594/3) for financial support and the award of a Leadership Fellowship (AFL) and studentship (AM). Computational resources for this project were partially provided by UK's National highperformance computing service, HECToR (EP/F067496) through the materials consortium, ARCCA and HPC-Wales supercomputer facilities. We thank Dr Adam Thetford and Soon Wen Hoh for discussions on the charge analysis carried out as part of this work.

\section{Notes and references}

1 D. G. Lee and U. A. Spitzer, J. Org. Chem., 1970, 35, 3589.

2 P. V. Prabhakaran, S. Venkatachalam and K. N. Ninian, Eur. Polym. J., 1999, 35, 1743.

3 J. Muzart, Tetrahedron, 2003, 59, 5789.

4 C. Della Pina, E. Faletta, L. Prati and M. Rossi, Chem. Soc. Rev., 2008, 37, 2077.

5 K. Mori, K. Yamaguchi, T. Hara, T. Mizugaki, K. Ebitani and K. Kaneda, J. Am. Chem. Soc., 2002, 124, 11572.

6 S. F. J. Hackett, R. M. Brydson, M. H. Gass, I. Harvey, A. D. Newman, K. Wilson and A. F. Lee, Angew. Chem., Int. Ed., 2007, 46, 8593.

7 D. I. Enache, J. K. Edwards, P. Landon, B. Solsona-Espriu, A. F. Carley, A. A. Herzing, M. Wantanabe, C. J. Kiely, D. W. Knight and G. Hutchings, Science, 2006, 311, 362.

8 D. I. Enache, D. W. Knight and G. Hutchings, Catal. Lett., 2005, 103, 43.

9 A. F. Lee, S. F. J. Hackett, G. J. Hutchings, S. Lizzit, J. Naugthon and K. Wilson, Catal. Today, 2009, 145, 251.

10 T. Balcha, J. R. Strobl, C. Fowler, P. Dash and R. W. J. Scott, ACS Catal., 2011, 1, 425.

11 H. Tsunoyama, H. Sakurai, Y. Negishi and T. Tsukuda, J. Am. Chem. Soc., 2005, 127, 9374.

12 A. F. Lee, C. V. Ellis, J. N. Naughton, M. A. Newton, C. M. A. Parlett and K. Wilson, J. Am. Chem. Soc., 2011, 133, 5724.

13 C. V. Gaskell, C. M. A. Parlett, M. A. Newton, K. Wilson and A. F. Lee, ACS Catal., 2012, 2, 2242.

14 A. F. Lee, J. N. Naughton, Z. Liu and K. Wilson, ACS Catal., 2012, 2, 2235.

15 C. M. A. Parlett, C. V. Gaskell, J. N. Naughton, M. A. Newton, K. Wilson and A. F. Lee, Catal. Today, 2013, 205, 76.

16 A. F. Lee, Z. Chang, P. Ellis, S. F. J. Hackett and K. Wilson, J. Phys. Chem. C, 2007, 111, 18844.

17 J. Naughton, A. F. Lee, S. Thompson, C. P. Vinod and K. Wilson, Phys. Chem. Chem. Phys., 2010, 12, 2670.

18 C. Stegelmann, N. C. Schiodt, C. T. Campbell and P. Stoltze, J. Catal., 2004, 221, 630.

19 Y.-H. Chin and E. Iglesia, J. Phys. Chem. C, 2011, 115, 17845. 20 Y.-H. Chin, C. Buda, M. Neurock and E. Iglesia, J. Am. Chem. Soc., 2011, 133, 15958.

21 M. Boronat and A. Corma, J. Catal., 2011, 284, 138.

22 J. Haubrich, D. Loffreda, F. Delbecq, Y. Jugnet, P. Sautet, A. Krupski, C. Becker and K. Wandelt, Chem. Phys. Lett., 2006, 433, 188.

23 F. Delbecq and P. Sautet, J. Catal., 2002, 211, 398.

24 F. Delbecq and P. Sautet, J. Catal., 2003, 220, 115.

25 J. Naughton, A. Pratt, C. W. Woffinden, C. Eames, S. P. Tear, S. M. Thompson, A. F. Lee and K. Wilson, J. Phys. Chem. C, 2011, 115, 25290. 
26 H. J. Monkhorst and J. D. Pack, Phys. Rev. B: Solid State, 1976, 13, 5188.

27 G. Kresse and J. Furthmüller, Phys. Rev. B: Condens. Matter Mater. Phys., 1996, 54, 11169.

28 G. Kresse and J. Hafner, Phys. Rev. B: Condens. Matter Mater. Phys., 1993, 47, 558.

29 J. P. Perdew, K. Burke and M. Ernzerhof, Phys. Rev. Lett., 1996, 77, 3865.

30 G. Kresse and D. Joubert, Phys Rev. B, 1999, 59, 1758.

31 P. E. Blöchl, Phys. Rev. B: Condens. Matter Mater. Phys., 1994, 50, 17953.

32 M. J. Frisch, G. W. Trucks, H. B. Schlegel, G. E. Scuseria, M. A. Robb, J. R. Cheeseman, G. Scalmani, V. Barone, B. Mennucci, H. Nakatsuji, G. A. Petersson, M. Caricato, X. Li, H. P. Hratchian, A. F. Izmaylov, J. Bloino, G. Zheng, J. L. Sonnenberg, M. Hada, M. Ehara, K. Toyota, R. Fukuda, J. Hasegawa, M. Ishida, T. Nakajima, Y. Honda, O. Kitao, T. Vreven, H. Nakai, J. A. Montgomery Jr., J. E. Peralta, F. Ogliaro, M. Bearpark, J. J. Heyd, E. Brothers, K. N. Kudin, V. N. Staroverov, R. Kobayashi, J. Normand, K. Raghavachari, A. Rendell, J. C. Burant, S. S. Iyengar, J. Tomasi, M. Cossi, N. Rega, J. M. Millam, M. Klene, J. E. Knox, V. Bakken, J. B. Cross, C. Adamo, J. Jaramillo, R. Gomperts, R. E. Stratmann, O. Yazyev, A. J. Austin, R. Cammi, C. Pomelli, J. W. Ochterski, K. Morokuma, R. L. Martin, V. G. Zakrzewski, G. A. Voth, P. Salvador, J. J. Dannenberg, S. Dapprich, A. D. Daniels, Ö. Farkas, J. B. Foresman, J. V. Ortiz, J. Cioslowski and D. J. Fox, R. C. Gaussian 09, Gaussian, Inc., Wallingford, CT, 2009.

33 A. D. Becke, J. Chem. Phys., 1993, 98, 5648.

34 C. T. Lee, W. T. Yang and R. G. Parr, Phys. Rev. B: Condens. Matter Mater. Phys., 1988, 37, 785.

35 K. A. Peterson, D. E. Woon and T. H. Dunning Jr., J. Chem. Phys., 1994, 100, 7410.
36 R. F. W. Bader, Atoms in Molecules - A Quantum Theory, Oxford University Press, Oxford, 1990.

37 W. Tang, E. Sanville and G. Henkelman, J. Phys.: Condens. Matter, 2009, 21, 084204.

38 M. Suzuki and K. Kozima, Bull. Chem. Soc. Jpn., 1969, 42, 2183.

39 A. Maeland and T. B. Flanagan, Can. J. Phys., 1964, 42, 2364.

40 A. Roldán, S. González, J. M. Ricart and F. Illas, ChemPhysChem, 2009, 10, 348.

41 L. Alves, B. Ballesteros, M. Boronat, J. R. Cabrero-Antonino, P. Concepción, A. Corma, M. A. Correa-Duarte and E. Mendoza, J. Am. Chem. Soc., 2011, 133, 10251.

42 A. Franceschetti, S. J. Pennycook and S. T. Pantelides, Chem. Phys. Lett., 2003, 374, 471.

43 K. L. Howard and D. J. Willock, Faraday Discuss., 2011, 152, 135.

44 C. D. Zeinalipour-Yazdi, A. L. Cooksy and A. M. Efstathiou, Surf. Sci., 2008, 602, 1858.

45 D. F. Mukhamedzyanova, N. K. Ratmanova, D. A. Pichugina and N. E. Kuz'menko, J. Phys. Chem. C, 2012, 116, 11507.

46 A. A. Herzing, C. J. Kiely, A. F. Carley, P. Landon and G. J. Hutchings, Science, 2008, 321, 1331.

47 M. S. Chen and D. W. Goodman, Science, 2004, 306, 252.

48 M. Amft, B. Johansson and N. V. Skorodumova, J. Chem. Phys., 2012, 136, 024312.

49 A. Lyalin and T. Taketsugu, J. Phys. Chem. C, 2009, 114, 2484.

50 K. J. Taylor, C. L. Pettiette-Hall, O. Cheshnovsky and R. E. Smalley, J. Chem. Phys., 1992, 96, 3319.

51 H. Häkkinan and U. Landman, Phys. Rev. B: Condens. Matter Mater. Phys., 2000, 62, R2287.

52 S. Linic and M. A. Barteau, J. Am. Chem. Soc., 2002, 124, 310. 